RASĀYAN J. Chem.

Vol. 13 | No. 1 |177 - 187| January - March | 2020 ISSN: 0974-1496 | e-ISSN: 0976-0083 | CODEN: RJCABP http://www.rasayanjournal.com http://www.rasayanjournal.co.in

\title{
ISOLATION AND CHARACTERISATION OF CELLULOSE NANOCRYSTAL OBTAINED FROM SUGARCANE PEEL
}

\author{
C. V. Abiaziem ${ }^{1,2, *}$, A. B. williams ${ }^{1}$, A. I. Inegbenebor ${ }^{1}$, C. T. Onwordi ${ }^{3,4}$, \\ C. O. Ehi-Eromosele ${ }^{1}$ and L. F. Petrik ${ }^{3}$ \\ ${ }^{1}$ Department of Chemistry, Covenant University, Km 10, Canaan Land, Ota, \\ P.M.B 1023, Ota, Ogun State, Nigeria \\ ${ }^{2}$ Science Laboratory Technology Department, The Federal Polytechnic Ilaro, \\ P.M.B 50, Ilaro, Ogun State, Nigeria \\ ${ }^{3}$ Department of Chemistry, Environmental and Nano Sciences Group, University of the Western \\ Cape, Bellville, Cape Town, 7535, South Africa \\ ${ }^{4}$ Department of Chemistry, Lagos State University, Ojo, LASU P. O. Box 0001, \\ Ojo, Lagos State, Nigeria \\ *E-mail: vyvycox@yahoo.com
}

\begin{abstract}
This work was aimed at developing efficient and stable cellulose nanocrystal (CNC) from sugarcane peel, which has been of growing concern as a potential for various industrial applications and providing a solution to the problem of indiscriminate disposal of peels of sugarcane, which creates nuisance in the environment. The alkaline treatment with sodium hydroxide and bleaching with acidified sodium chlorite were used to isolate cellulose from sugarcane peel, followed by acid hydrolysis which was done at $45^{\circ} \mathrm{C}$ for $45 \mathrm{~min}$ using $64 \%$ sulphuric acid to prepare the CNC. The chemical composition of the samples and their physicochemical properties were studied. The untreated and treated samples were characterised using various techniques, scanning electron microscopy (SEM), x-ray diffraction (XRD), transmission electron microscopy (TEM), Fourier transformed infrared spectroscopy (FT-IR) and thermogravimetric analysis (TGA). The CNC exhibited FT-IR spectra identified as cellulose structures. XRD showed that the CNC earmarked the structure of the cellulose nanocrystal with a crystallinity index of $99.2 \%$. The SEM micrograph revealed fiber bundles separated into individualized CNC; the TEM image showed a needleshaped CNC with a particle size of $20.57 \mathrm{~nm}$ and $153.05 \mathrm{~nm}$ in diameter and length, respectively. The TGA curve revealed a good thermal stability for the CNC. The results showed an effective synthesis of CNC from sugarcane peel. This material, therefore, has potential for diverse industrial applications including wastewater treatment, food wrapping and bionanocomposite for biomedical.
\end{abstract}

Keywords: Sugarcane Peel, Cellulose, Cellulose Nanocrystal, Acid Hydrolysis, Characterization

(C) RASĀYAN. All rights reserved

\section{INTRODUCTION}

In recent times, the alteration of agricultural waste into value products has been an increasing research study, this agricultural solid waste has become one environmental problem currently and researchers are concerned about the use of agro solid waste to enhance value-added products. This has led to several efforts to convert waste to wealth concept all over the world. ${ }^{1,2}$ Reduced-cost and high-performance cellulose nanomaterial from renewable and ecological resources is a growing research area. ${ }^{1}$ In this study, the preparation of cellulose nanocrystal from sugarcane peel sorted from Ogun State, Nigeria is a novel material with unique properties such as reduced toxicity, low density, low heat expansion, high aspect ratio, large surface area, high tensile strength, excellent mechanical properties and hydroxyl groups $(-\mathrm{OH})$ on the surfaces that could be readily chemically functionalized. ${ }^{4,5}$ Nanoparticles are promising potentials in several applications due to their unusual characteristics when likened to their bulk materials, they can

Rasayan J. Chem., 13(1), 177-187(2020)

http://dx.doi.org/10.31788/RJC.2020.1315328

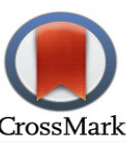


RASĀYAN J. Chem.

Vol. 13 | No. 1 |177 - 187| January - March | 2020

be synthesised using several methods, such as cell membrane, liquid phase chemical precipitation, sublimation among others. ${ }^{6,7}$ In general, the cell walls of plants comprises primarily of three organic compounds: cellulose, hemicellulose, and lignin. These organic compounds are the main components of natural lignocellulosic materials. ${ }^{5,8}$ However both hemicellulose and lignin are non-crystalline fibers. Hydrolysis of the acid process removes the non-crystalline domain and extraction of nanocellulose crystals from untreated fibers. ${ }^{9,10}$

Cellulose constitutes of $\beta$-1, 4-linked anhydro-D-glucose units and has hydroxyl (-OH) groups that make it build bonds of hydrogen which are strong. In previous literature, many sources of cellulose, such as cotton, banana rachis, sugarcane bagasse, soy hulls, corncob, cassava bagasse, wood, hemp, mengkuang leaves (Pandanus tectorius), rice husk, kapok fruit, jute, sweet potatoes residue, capim dourado etc have been used in preparing $\mathrm{CNCs}^{5}$. Several other resources such as palm kernel shell, coconut shell and bamboo have been used in making activated carbon filter for the treatment of polluted water. ${ }^{11}$ Cellulose Nanocrystal prepared from sulphuric acid hydrolysis of polymer fibers is known to be a novel cluster of nanomaterials. $\mathrm{CNC}$ has several benefits, such as nano dimension, high specific strength and modulus, large surface area, distinctive optical properties and low coefficient of thermal expansion. ${ }^{12,13}$ These extremely crystalline cellulose obtained from sulfuric acid hydrolysis are usually between 5-30 nm in diameter ${ }^{14,15}$ and possess sulfate groups that are negatively charged on their surface. In recent times, the synthesis and characterisation of novel functional nanomaterial have subjected the area of materials science over the last decade. ${ }^{16}$

Sugarcane is a giant tropical grass from the family Graminaceae, its stalk is capable of storing crystallisable sugar, sucrose and it is processed to make rum. The stems and peels are rich in cellulose and lignin which have many uses in the green chemical industry. Several studies have shown that sugarcane peel is a renewable material rich in different molecular species of antioxidants and contains a considerable amount of wax. ${ }^{17,18}$ The peel and bagasse of sugarcane are residues produced in large mass annually by sugar and alcohol industries ${ }^{19}$, hence, the indiscriminate disposal of these residues creates a nuisance in the environment. Several studies have worked on sugarcane bagasse as cellulose nanocrystal and they have shown to have huge potentials in various polymer composite applications. However, to the best of our knowledge, no study on sugarcane peel cellulose nanocrystal has been found in the literature.

The present study was aimed at adding value to sugarcane by using its peel to isolate cellulose and cellulose nanocrystal via sulphuric acid hydrolysis, using $64 \% \mathrm{H}_{2} \mathrm{SO}_{4}$ at $45^{\circ} \mathrm{C}$ for $45 \mathrm{~min}$ in order to obtain a material with high crystallinity index, thermal stability and surface morphology (shape and size). The benefits of using sulphuric acid for hydrolysis treatment is attributed to the fact that sulphuric acid contributes to the isolation of crystalline particles and stable aqueous suspensions of $\mathrm{CNCs}$, due to its negatively charged sites, hence do not tend to agglomerate ${ }^{9}$, a reaction time of $45 \mathrm{~min}$ and temperature of $45^{\circ} \mathrm{C}$ showed a reduced polydisperse length distribution, high crystallinity and smallest crystals. ${ }^{20}$ To examine the probable use of cellulose nanocrystal isolated from the sugarcane peel as a prospect for various industrial applications, their chemical composition and physicochemical analysis was determined, it was further characterised by Fourier transform infrared spectroscopy (FT-IR), x-ray diffraction (XRD), thermogravimetric analysis (TGA) and zeta potential. The morphological structures of the cellulose and nanocrystal were investigated by scanning and transmission electron microscopy.

\section{EXPERIMENTAL}

\section{Materials and Methods}

The sugarcane peel sample used in this study was collected from different sugarcane farms in Papalanto and Sagamu area in Ogun State, Nigeria. The sample was prepared by washing with water, air-dried, milled and sieved with a +30 -mesh screen. Reagents used were; sodium chlorite, sulphuric acid, toluene, ethanol, sodium hydroxide and acetic acid. All the reagents were analytical grade and were purchased from Sigma Aldrich and Merck South Africa.

\section{Isolation of Chemically Purified Cellulose (CPC) From Sugarcane Peel}

Chemically purified cellulose (CPC) from sugarcane peel was isolated as described elsewhere. ${ }^{21,22}$ The clean dried sample $(30 \mathrm{~g})$ was extracted with $2: 1 \mathrm{v} / \mathrm{v}$ mixture of toluene and ethanol mixture for $6 \mathrm{~h}$ 
RASĀYAN J. Chem.

Vol. 13 | No. 1 |177 - 187| January - March | 2020

to remove wax, it was oven-dried at $60^{\circ} \mathrm{C}$ for $16 \mathrm{~h}$. The dewaxed sample was soaked in $50 \mathrm{~g} / \mathrm{L}$ of $5 \%$ sodium hydroxide solution at $25^{\circ} \mathrm{C}$ for $24 \mathrm{~h}$ and at $90^{\circ} \mathrm{C}$ for $2 \mathrm{~h}$ to remove hemicellulose and silica. This was rinsed with the plentiful volume of distilled water until the filtrate became neutral, followed by ovendrying at $50^{\circ} \mathrm{C}$ for $16 \mathrm{~h}$. The residual alkaline treated sample was delignified using $2.5 \% \mathrm{w} / \mathrm{v}$ of acidified sodium chlorite at $\mathrm{pH} 4$ using the material to liquor ratio of $1: 20$ for $4 \mathrm{~h}$ at $100^{\circ} \mathrm{C}$. The delignified cellulose was washed with distilled water to remove the excess chemicals and oven-dried at $50^{\circ} \mathrm{C}$ for 16 h. Finally, the product (CPC) was stored in an air-tight container.

\section{Preparation of Cellulose Nanocrystal (CNC)}

Cellulose nanocrystal was prepared via sulphuric acid-hydrolysis as described elsewhere. ${ }^{4,9,14,21,23}$ The cellulose isolated from sugarcane peel was hydrolyzed with $64 \mathrm{wt} \%$ sulfuric acid in a ratio of $10 \mathrm{~mL} / \mathrm{g}$ at a temperature of $45^{\circ} \mathrm{C}$ for 45 min with vigorous mechanical stirring. The reaction of hydrolysis was quenched with 10-fold cold water. The resultant cellulose nanocrystal gel was centrifuged at $45000 \mathrm{rpm}$ for $30 \mathrm{~min}$ to concentrate the cellulose nanocrystal and to remove surplus acid, the filtrate was then decanted. The resultant precipitate was dialysed with cellulose dialysis tube against ultra-pure water until neutral $\mathrm{pH}$ was attained ( $\mathrm{pH}$ 6-7). The suspension was sonicated at an amplitude of $40 \%$ in an ice bath to disrupt solid aggregates and avoid overheating. The resultant $\mathrm{CNC}$ suspension was freeze-dried $\left(-47^{\circ} \mathrm{C}\right.$, 0.2 mbar). The dried sample was stored in an air-tight container for characterisation. Below is the photograph of the sugarcane plant and peel.

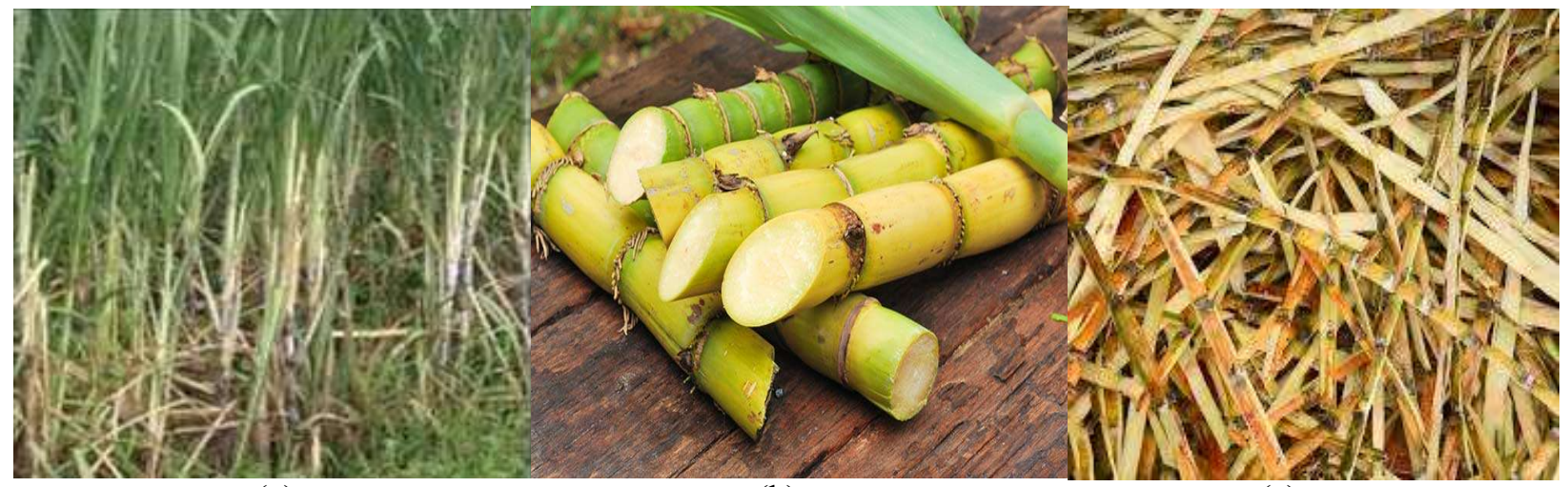

(a)

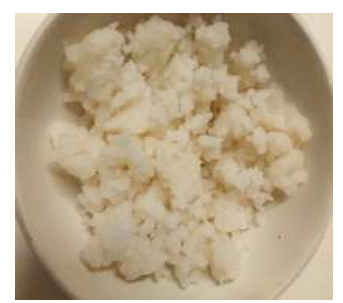

(d) (b)

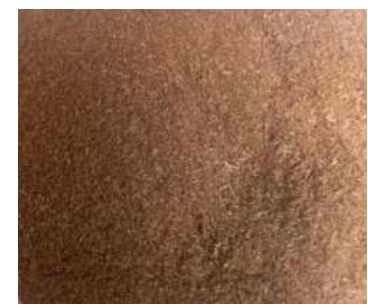

(e) (c)

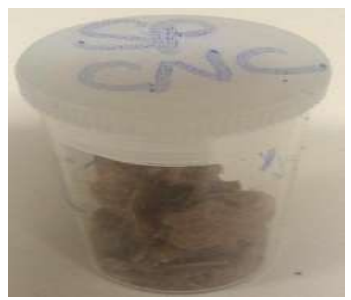

(f)

Fig.-1: Photograph of (a) Sugarcane Plant (b) Sugarcane Stems (c) Sugarcane Peels (d) Raw Sugarcane Peel Fibres

\section{Analysis of Chemical Composition}

(e) Sugarcane Peel Cellulose (f) Sugarcane Peel Nanocrystal

The chemical compositions of sugarcane peel were determined according to the method by ${ }^{24}$. The raw fiber, alkali-treated fiber and the bleached fiber were measured at different stages of treatment. The percentage extractives (wax), percentage hollocellulose, percentage lignin and percentage cellulose were determined.

\section{Fourier Transform Infra-Red Spectroscopy (FT-IR)}

FT-IR was used to evaluate the functional groups of the various products at each stage of extraction. The PerkinElmer spectrum 400 FT-IR/FT-NIR spectrometer was programmed to scan 60 times at a resolution of $2.0 \mathrm{~cm}^{-1}$ over the wavelength range of $4000 \mathrm{~cm}^{-1}$ to $650 \mathrm{~cm}^{-1}$ against the transmittance. 
RASĀYAN J. Chem.

Vol. 13 | No. 1 |177 - 187| January - March | 2020

\section{High-Resolution Scanning Electron Microscopy (HR-SEM)}

AURIGA field emission high-resolution scanning electron microscope, Zeiss, Germany was used to analyze the surface morphology of the untreated, cellulose and nanocrystal. The samples were prepared by coating with carbon to make SEM analysis conductive. The sample images from HRSEM were taken at different magnification.

\section{Transmission Electron Microscopy (HR-TEM)}

The sample was prepared by drop-coating one drop of specimen solution on a carbon-coated copper grid. This was then dried under a xenon lamp for $10 \mathrm{~min}$, after which the sample coated with grids was analyzed under a microscope. Transmission electron micrograph was collected using HR-TEM (HighResolution Transmission Electron Microscope) FEI Tecnai G2 F20 X-Twin MAT, field emission gun (FEG), Germany, functioned in light-up field mode at a speed up the voltage of $200 \mathrm{kV}$.

\section{X-ray Diffraction (XRD)}

$\mathrm{X}$-ray was carried out using Philips X-pert MPD X-ray diffractometer with $\mathrm{Cu}-\mathrm{K}$ radiation operating at $40 \mathrm{kV}$ and $40 \mathrm{Ma}$, to identify the crystallinity nature of a material. The sample was scanned over a range of $5^{\circ}$ to $70^{\circ}$ at $2 \theta$ with the count step size programmed at 0.5 seconds per step $/ 0.05$ step size. The crystallinity index $(\mathrm{CI})$ was evaluated from the maximum intensity of the principle peak of $200\left(\mathrm{I}_{002}, 2 \theta=\right.$ $\left.22^{\circ}\right)$ and the intensity of diffraction of 110 peaks $\left(I_{a m}, 2 \theta=16^{\circ}\right)$ using the Segal method ${ }^{25,26}$.

$\mathrm{I}_{002}$ represents both crystalline and amorphous material, whereas $\mathrm{I}_{\mathrm{am}}$ represents the amorphous material.

$$
\mathrm{CI}(\%)=\frac{\mathrm{I}_{002}-\mathrm{I}_{\mathrm{am}}}{\mathrm{I}_{002}} \times 100
$$

\section{Thermogravimetric Analysis (TGA)}

Thermal stability of the untreated and treated samples was performed using PerkinElmer thermogravimetric analyzer TGA 4000, Waltham, USA. The analysis of the TGA was examined under a nitrogen atmosphere and the thermal speed of the sample was set at room temperature, $25^{\circ} \mathrm{C} / \mathrm{min}$ up to $700^{\circ} \mathrm{C}$ and held for $1 \mathrm{~min}$ at $700^{\circ} \mathrm{C}$.

\section{Physicochemical Properties of Cellulose Nanocrystal Moisture Content (MC)}

The raw sugarcane peel (RSP), sugarcane peel chemically purified cellulose (SPCPC) and sugarcane peel cellulose nanocrystal (SPCNC) of $0.5 \mathrm{~g}$ each were measured into a crucible. This was oven-dried for $5 \mathrm{~h}$ at a constant temperature of $105^{\circ} \mathrm{C}$ until a steady mass was achieved. The change between the mass constituents was calculated as shown in equation (2).

$$
\begin{aligned}
& \% \text { moisture content }=\frac{\mathrm{m}_{2}-\mathrm{m}_{3}}{\mathrm{~m}_{2}-\mathrm{m}_{1}} \times 100 \\
& \text { Where, } m_{1}=\text { mass of the crucible with lid } \\
& m_{2}=\text { mass of crucible with lid and sample before drying } \\
& m_{3}=\text { mass of the crucible with lid and sample after drying }
\end{aligned}
$$

Swelling capacity, water holding capacity and oil holding capacity; were carried out according to the method reported by. ${ }^{27,28}$

\section{Chemical Composition}

\section{RESULTS AND DISCUSSION}

The chemical compositions of the sugarcane peel at different stages of treatment are shown in Table 1 . The results revealed that the sugarcane peel fibre consist of $7.15 \pm 0.01 \%$ cellulose, $27.522 \pm 0.015 \%$ hemicellulose, $47.733 \pm 0.025 \%$ lignin and $17.592 \pm 0.055 \%$ extractives. Hemicellulose was removed by alkaline treatment. The value obtained for lignin was expected since sugarcane peel has high stiffness. Lignin lends rigidity and does not rot, rather they display strength to natural fibres ${ }^{34}$. The lignin was removed by bleaching with acidified sodium chlorite. Hemicellulose and lignin removal from sugarcane peel affected the cleavage of the ester-linked substance of hemicellulose, thereby increasing the surface area of the sugarcane fiber and making polysaccharides more susceptible to acid hydrolysis. The 
RASĀYAN J. Chem.

Vol. 13 | No. 1 |177 - 187| January - March | 2020

modifications of the chemical composition of sugarcane peel fiber after all treatment gave rise to a good crystalline structure of cellulose, hence enhanced the strength and heat properties of the fibre. ${ }^{9,29}$

Table-1: Chemical Composition of Sugarcane Peel

\begin{tabular}{c|c|c|c|c}
\hline Sample & Cellulose (\%) & Hemicellulose( \%) & Lignin (\%) & Extractives (\%) \\
\hline Sugarcane peel & $7.15 \pm 0.01$ & $27.522 \pm 0.015$ & $47.733 \pm 0.025$ & $17.592 \pm 0.055$ \\
\hline
\end{tabular}

\section{Physicochemical Properties \\ Moisture Content}

Moisture content is an important characteristic that must be determined as potential adsorbent, biocomposite, food packaging, and various industrial applications. It is applied to evaluate the properties and the final applications of fiber materials. Increased water in the fibers might deteriorate the constancy of the cellulose materials in footings of tensile strength, the formation of porosity and size. ${ }^{9,30,31,32}$ Table 2 shows the moisture content of the RSP, SPCPC and SPCNC to be, $11.24 \pm 0.01,7.001 \pm 0.005$ and $6.133 \pm 0.005$, respectively. The raw sample had higher moisture content when compared to the treated samples. This may be due to the presence of more hydroxyl functional groups in the parent material than in the CPC and CNC, hence the interaction with water molecules may have arisen from the high hydroxyl group content, providing it with a higher hydration property. ${ }^{28}$

\section{Swelling capacity (SC)}

The raw sample had a higher swelling capacity when compared to the treated sample of sugarcane peel. Table 2 revealed the results as follows; $3.05 \pm 0.05,2.55 \pm 0.05$ and $0.50 \pm 0.01 \mathrm{~mL} / \mathrm{g}$ for RSP, SPCPC, and SPCNC, respectively, this tallies with the result revealed by ${ }^{28}$, this could be due to the presence of hydroxyl functional groups in the parent material than the CPC and $\mathrm{CNC}$, hence, the higher hydroxyl group content gave rise to a higher hydration property. ${ }^{28}$

\section{Water Holding Capacity (WHC)}

The results obtained as shown in Table 2 are as follows; $3.59 \pm 0.05,4.08 \pm 0.05$ and $5.70 \pm 0.05 \mathrm{~g} / \mathrm{g}$ for RSP, SPCPC, and SPCNC, respectively. The trend of the results were similar to that reported by ${ }^{27}$. The treated cellulose nanocrystal exposed further surface area to its immediate surroundings. ${ }^{33,34}$ The higher water holding capacity of the nanocrystal over the raw and the chemically purified cellulose of sugarcane peel suggests the possible use of SPCNC in waste water treatment (adsorbents) and in food applications where low moisture retention is required. ${ }^{28,27}$

\section{Oil Holding Capacity (OHC)}

The oil holding capacity of the $\mathrm{CNC}$ of sugarcane peel was higher than the raw sample. The $\mathrm{OHC}$ of the RSP, SPCPC, and SPCNC are $5.05 \pm 0.05,5.55 \pm 0.05$ and $11.05 \pm 0.05 \mathrm{~mL} / \mathrm{g}$, respectively as presented in Table 2. These indicate that the breaking down of the cellulose dimension and bulk density with the introduction of sulphate group during acid hydrolysis might have increased the permeability and surface area of the material, improve and promote the physical trap of oil and the degree of oil holding capacity. ${ }^{28,34,35}$ Thus, the SEM image result further confirms the assertion due to the compact structure of the raw samples. The increased OHC of the cellulose nanocrystal showed their importance in the food industry and in bioremediation of oil spill. ${ }^{34}$

Table-2: Physicochemical Properties of Treated and Untreated Sugarcane Peel

\begin{tabular}{c|c|c|c|c}
\hline Sample & SC $(\mathrm{mL} / \mathrm{g})$ & WHC $(\mathrm{g} / \mathrm{g})$ & OHC $(\mathrm{mL} / \mathrm{g})$ & MC $(\%)$ \\
\hline RSP & $3.05 \pm 0.05$ & $3.59 \pm 0.05$ & $5.05 \pm 0.05$ & $11.24 \pm 0.01$ \\
\hline SPCPC & $2.55 \pm 0.05$ & $4.08 \pm 0.05$ & $5.55 \pm 0.05$ & $7.001 \pm 0.005$ \\
\hline SPCNC & $0.50 \pm 0.01$ & $5.70 \pm 0.05$ & $11.05 \pm 0.05$ & $6.133 \pm 0.005$ \\
\hline
\end{tabular}

Values are means of two determinations \pm SD.

\section{Fourier Transform Infra-Red Spectroscopy (FT-IR)}

The FT-IR technique was analyzed to investigate the functional groups available in sugarcane peel (SP) and to study the modifications that ensued owing to several chemical treatments ${ }^{36,37}$. Fig. 2 presents the 
RASĀYAN J. Chem.

Vol. 13 | No. 1 |177 - 187| January - March | 2020

FT-IR spectra of raw, cellulose and nanocrystal of sugarcane peel. The absorption peaks at $1511 \mathrm{~cm}^{-1}$ signify the aromatic $\mathrm{C}-\mathrm{C}$ in-plane symmetrical stretching vibration of aromatic ring present in lignin ${ }^{15,39,40}$ and this peak disappeared in the spectra of SPCPC and SPCNC which is indicative of complete removal of lignin during delignification treatment.

The peak at $1240 \mathrm{~cm}^{-1}$ was present only in the raw sugarcane peel representing the $\mathrm{C}-\mathrm{O}$ out of plane stretching vibration of the aryl group present in lignin, this disappeared in the treated cellulose and nanocellulose. ${ }^{38,41}$ The peaks located at $897 \mathrm{~cm}^{-1}$ in all the spectra are denoted as cellulose arrangement of the carbohydrate, it is found in all the spectra irrespective of its treatment.

The band located at $1724 \mathrm{~cm}^{-1}$ in the spectrum of the raw sample and disappeared in the treated and nanocrystal was ascribed to $\mathrm{C}=\mathrm{O}$ stretching ${ }^{9}$. The disappearance of this band in FT-IR fiber of SPCPC and SPCNC showed the exclusion of the amorphous region during alkaline treatment, sodium chlorite treatment and acid hydrolysis ${ }^{41}$. The peaks between $3500 \mathrm{~cm}^{-1}$ and $3200 \mathrm{~cm}^{-1}$ represent the characteristic $\mathrm{OH}$ stretching of the treated and untreated cellulose ${ }^{38,36}$, which attested to the removal of lignin portion and improved cellulose crystallinity. The peak at $1155 \mathrm{~cm}^{-1}$ was due to the $\mathrm{C}=\mathrm{O}=\mathrm{C}$ stretching vibrations of the $\beta 1$, 4-glycosidic ring linkages ${ }^{42}$. Consequently, the peaks between $3100 \mathrm{~cm}^{-1}$ to $3700 \mathrm{~cm}^{-1}$ was assigned to the $\mathrm{OH}$ stretching vibration, the sharper peak of the nanocellulose denotes the removal of water. ${ }^{42}$ Stretching frequency at $2912 \mathrm{~cm}^{-1}$ was due to the symmetric $\mathrm{C}=\mathrm{H}$ vibration for all samples. ${ }^{23}$ The characteristic peaks at $1034 \mathrm{~cm}^{-1}$ and $1027 \mathrm{~cm}^{-1}$ confirm the presence of C-O-C pyranose ring in all the spectra. ${ }^{10}$

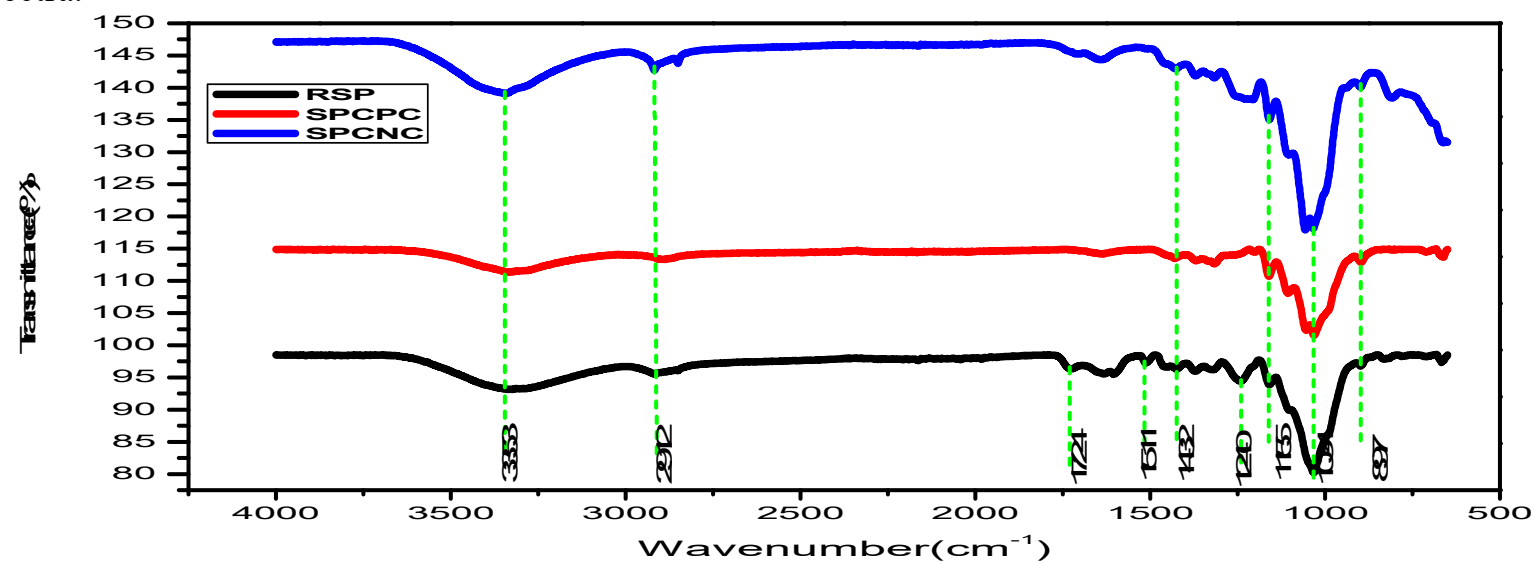

\section{SEM Analysis}

Fig.-2: FTIR Spectra of Raw Sugar Peel, Cellulose Fiber and Cellulose Nanocrystal

Figure-3 shows the SEM micrograph of sugarcane peel at different stages of processing. The smooth surface of the untreated sample (raw) of the sugarcane peel in Fig.-3a is based on the non-fibrous components in the material. The alkaline treatment reveals that the hemicellulose was hydrolyzed and became water-soluble, the fibrils were defibrillated. After chemical treatment of the raw fiber, a narrow fibril and reticular structure of the fiber which is then chemically purified cellulose was seen, indicating that the procedure of isolating the cellulose did not completely shatter the cellulose structure and remove impurities as shown in Fig.-3b.

The features of the cellulose nanocrystal showed that there was a reduction in the fibrillar structure size and intermittent breakdown in fibrillar structure into individualizing fibrils. Figure-3a and $3 \mathrm{~b}$ show the raw and the cellulose sample while Fig.-3c represents the freeze-dried cellulose nanocrystal, the structure of the cellulose was absolutely shattered and the size was considerably reduced to nano-size as pointed out by. ${ }^{27}$

\section{TEM Analysis}

The TEM micrograph in Fig.-4a showed that the SPCNC was needle-shaped, they are uniform nano dimension bundles of crystals and aggregate nanocrystals which may be attributed to the sulphate group emanated during acid hydrolysis of the cellulose fiber which was similar to that reported by. ${ }^{43}$ The diameter and length of the fiber was measured using Image $J$ software obtained from several TEM 
RASĀYAN J. Chem.

Vol. 13 | No. 1 |177 - 187| January - March | 2020

micrographs. The particle size had an average value of $20.57 \pm 9.47 \mathrm{~nm}$ in width and $153.05 \pm 70.8 \mathrm{~nm}$ in length, with a size range of 5.39-57.4 $\mathrm{nm}$ in width and 34.6-319.6 nm in length. ${ }^{21}$ The width measured were comparable in range to the nano-sized that were prepared from other wastes materials such as sugarcane bagasse $(35 \mathrm{~nm})^{38}$, rice straw $(11.2 \mathrm{~nm})^{14}$, Industrial wastes cotton $(10 \mathrm{~nm})^{1}$. The SPCPC in Fig.-3b showed a less clear morphology indicating the presence of an amorphous region as compared to the nanocrystal with a more crystalline region. The histograms of the TEM micrograph of SPCNC are shown in Fig.-4c, d (width and length), respectively.

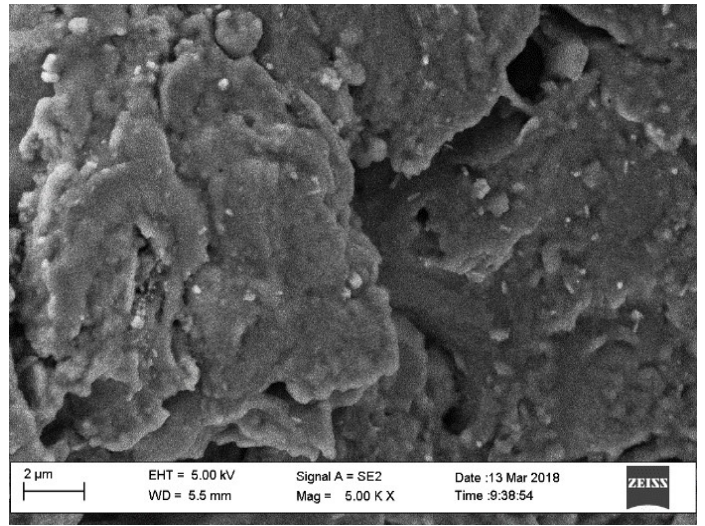

(a)

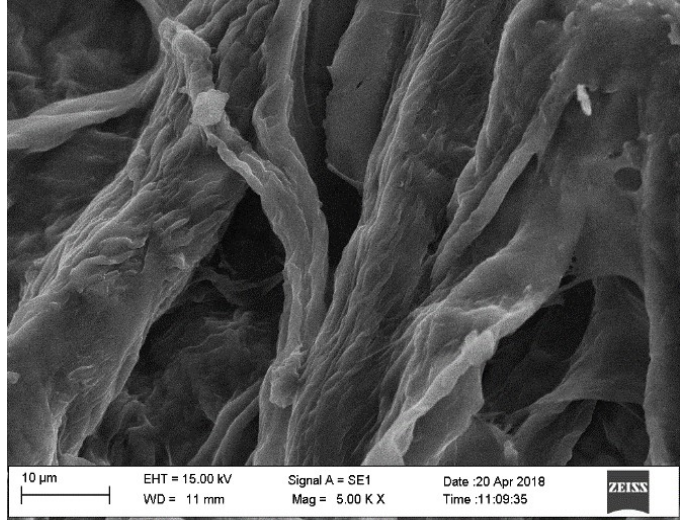

(b)

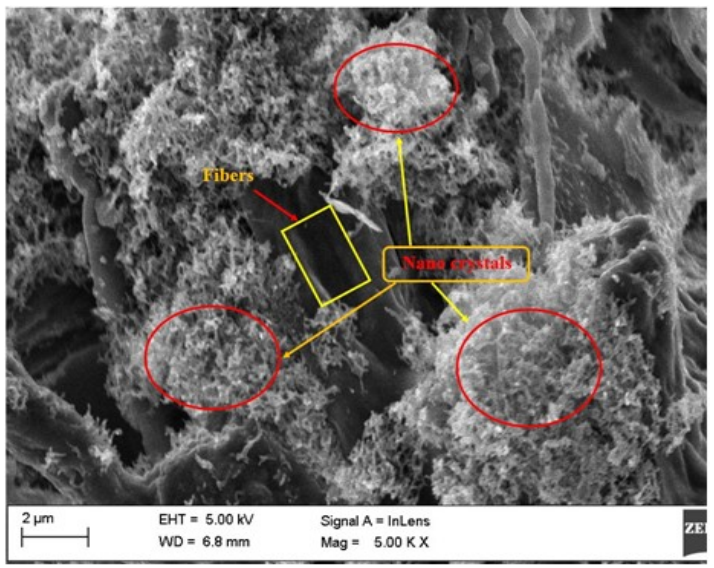

(c)

Fig.-3: SEM Micrograph of the(a) Raw Sample(b) Celulose(c) Nanocrystal of Sugarcane Peel

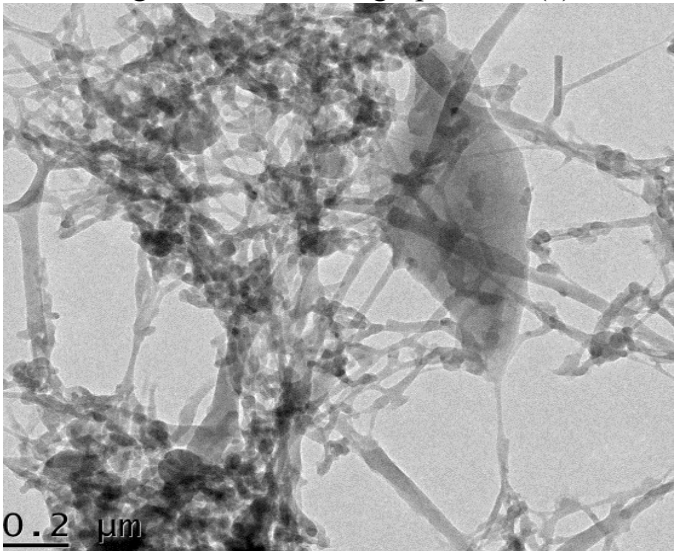

(a)

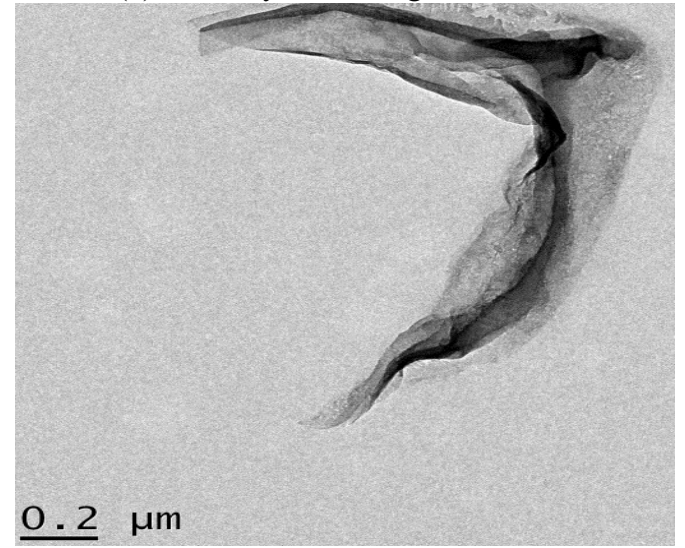

(b) 
RASĀYAN J. Chem.

Vol. 13 | No. 1 |177 - 187| January - March | 2020

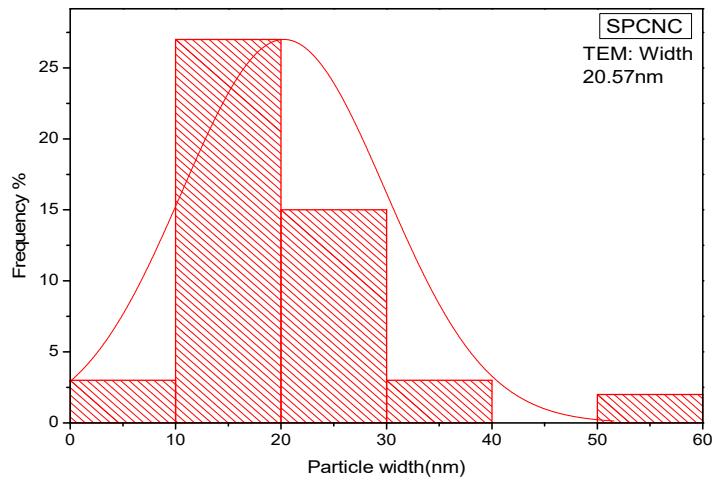

(c)

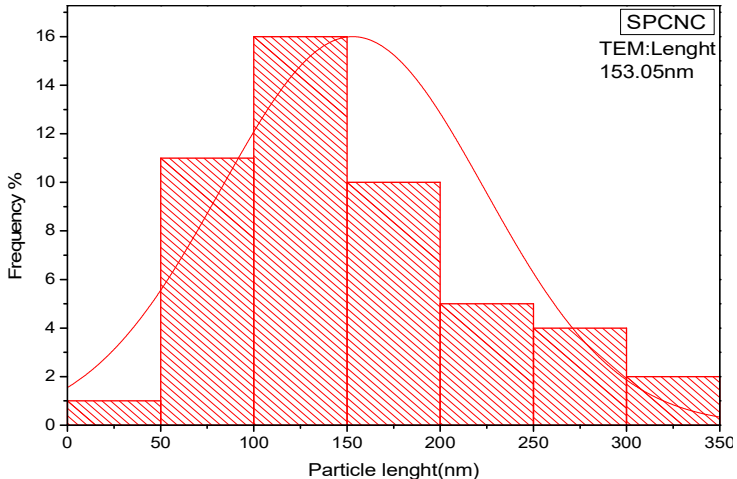

(d)

Fig.-4: TEM Micrograph of (a) CNC of Sugarcane Peel (b) Cellulose of Sugarcane Peel, Histogram of CNC (c)

\section{XRD Analysis}

Width (d) Length

Figure-5 shows the XRD patterns for sugarcane peel at different stages of treatment. The peak at $2 \theta=$ $22.5^{\circ}$ shows the crystallinity pattern of cellulose for all fibres ${ }^{21}$. The characteristic peak of RSP identified at $2 \theta=16.9^{\circ}$ and $34.7^{\circ}$ are 110 and 004 lattice planes of cellulose I indicating the presence of amorphous region. Also, the peak at $2 \theta=16.7^{\circ}$ of the SPCPC indicates the presence of the amorphous region and the disappearance of the peak at the lattice plane of 004 of the SPCPC indicates the partial removal of the amorphous region. The disappearance of peak at lattice plane 110 and 004 of the SPCNC indicates complete removal of the amorphous region. The crystallinity index of RSP, SPCPC and SPCNC was calculated to be $86.5 \%, 95.6 \%$, and $99.2 \%$ and crystallite size of $25.8 \mathrm{~nm}, 21.1 \mathrm{~nm}$ and $5.56 \mathrm{~nm}$, respectively. The benefits of having a high crystallinity index ( $>70 \%)$ comprise of the important increase of the chemical, thermal stability and bacteria resistance of the material. ${ }^{13}$ The crystallinity index increased progressively from the raw to the $\mathrm{CNC}$ which was similar to the result reported by ${ }^{44,45}$ The subsequent rise of the crystallinity index value during acid hydrolysis is indicative of the removal of amorphous cellulosic regions. ${ }^{44,46}$ Also, during the isolation of cellulose nanocrystal the progression and repositioning of nanocrystal may take place in equivalent and thus can enhance the cellulose crystallinity. ${ }^{43,44}$

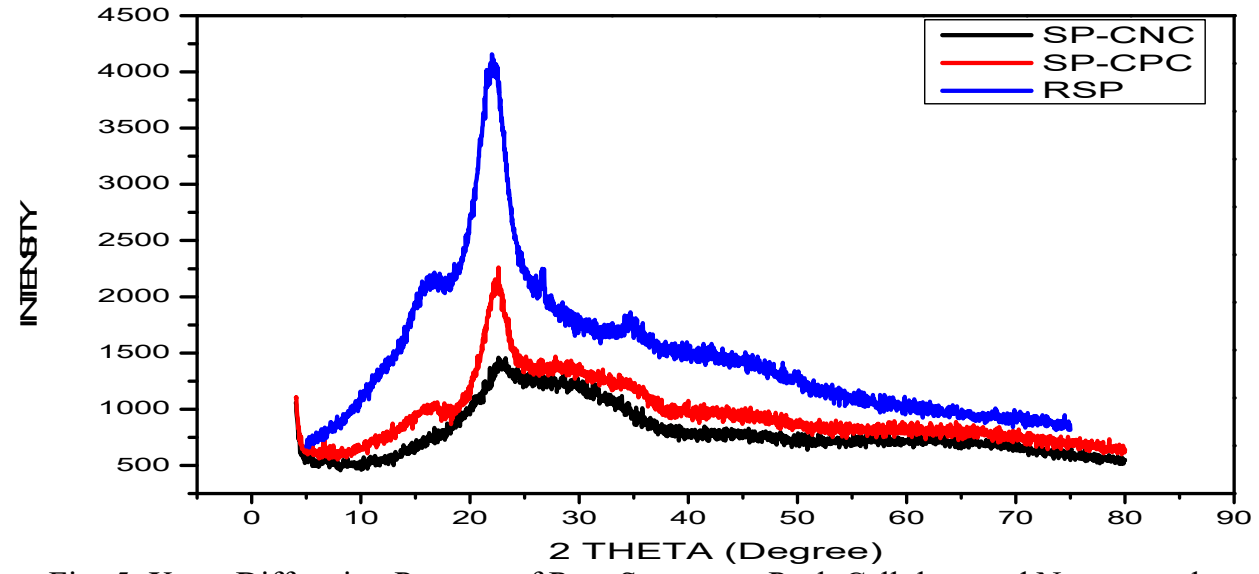

Fig.-5: X-ray Diffraction Patterns of Raw Sugarcane Peel, Cellulose and Nanocrystal

\section{Thermogravimetric Analysis (TGA)}

Figure-6a and 6b show the DTG and TGA, respectively of the raw, cellulose and cellulose nanocrystal of sugarcane peel fiber. As reported in the literature, chemical treatment with sulfuric acid leads to a notable decrease in the thermal stability of cellulose nanocrystal, the thermal stability of this crystal is a key factor in order for them to be used as effective application materials. ${ }^{47,48}$ The temperature of maximum degradation of the three fibers; RSP, SPCPC and SPCNC occurred at a temperature of $356.1^{\circ} \mathrm{C}, 357.9^{\circ} \mathrm{C}$ 
RASĀYAN J. Chem.

Vol. 13 | No. 1 |177 - 187| January - March | 2020

and $290.6^{\circ} \mathrm{C}$, respectively. The TGA graph showed that the SPCNC was less thermally stable because the presence of sulphate group on the surface of the acid hydrolyzed fiber has a catalytic effect in its reactions to heat breakdown. From the TGA curve, all the fibers showed an initial weight drop between 41.2$108.8^{\circ} \mathrm{C}$ due to the evaporation of water. The maximum thermal decomposition of the raw sample was divided into four phases due to the presence of the different cellulosic components of the fiber. ${ }^{42}$ The first phase was loss of moisture content which occurred at maximum temperature of $56.8^{\circ} \mathrm{C}$, next was the decomposition of lignocellulosic components of hemicellulose which occurred at $226.6^{\circ} \mathrm{C}$, followed by lignin which occurred at $314^{\circ} \mathrm{C}$ and finally cellulose which occurred at $356.1^{\circ} \mathrm{C}^{9,22}$, loss of weight started at a temperature around $41.2^{\circ} \mathrm{C}$ which was due to loss of water in all the samples. As fiber was heated, the material reduced in weight. ${ }^{9,49}$ The evaporation of water for the raw sample was completely removed at $120.8^{\circ} \mathrm{C}$, which was similar to that reported by ${ }^{9,47}$, water in the SPCPC was completely evaporated at a maximum temperature of $105.6^{\circ} \mathrm{C}$, this was due to high moisture content of the raw sample compared to the treated fibers. During the treatment of fibers, the weight loss was reduced due to lowered moisture content. $^{50,51}$

The SPCPC and SPCNC showed a temperature of maximum degradation of the component at $357.9^{\circ} \mathrm{C}$ and $290.6^{\circ} \mathrm{C}$, respectively, they also showed two and one inflation point respectively, indicating the purity of the treated materials. The results revealed that the fibers of the SPCNC which was treated with sulphuric acid degraded faster compared to SPCPC. This could be ascribed to the excess acid group in the SPCNC fibre ${ }^{48}$. It has been reported that the prompt decomposition temperature of the CNC was due to the hydrolysis process, thereby reducing the molecular weight drastically. Also, the treatment with sulphuric acid hydrolysis removes the amorphous region. ${ }^{38,23}$

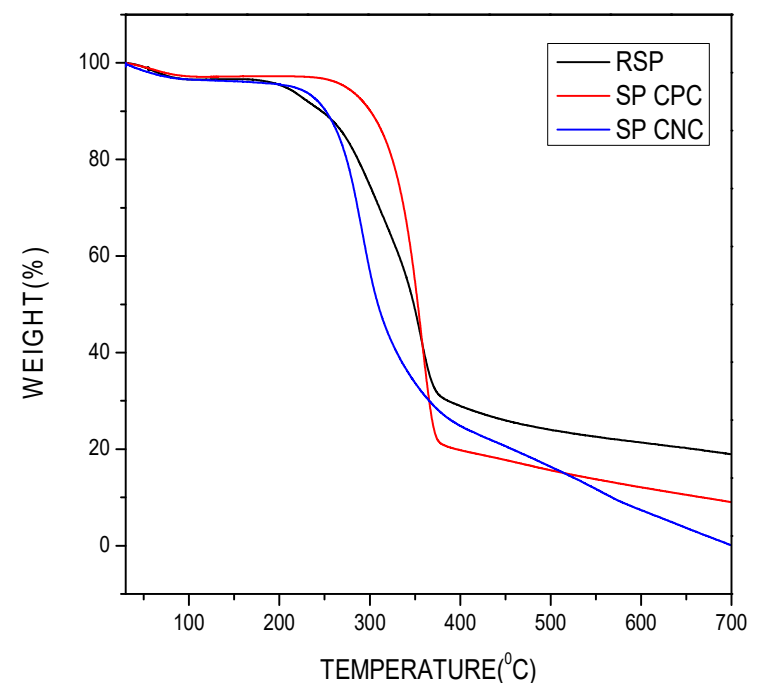

(a)

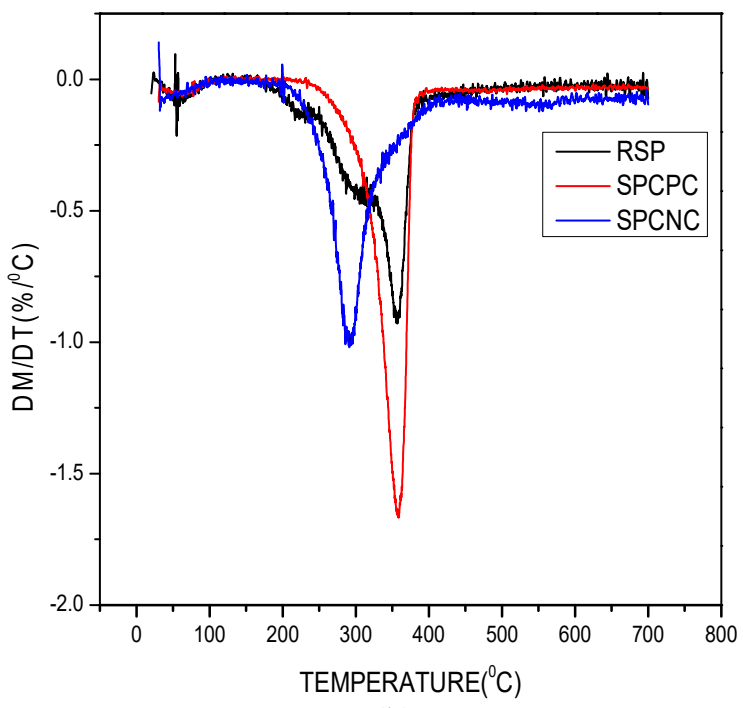

(b)

Fig.-6: (a) TGA and (b) DTG Curves for Raw, Cellulose and Nanocrystal of Sugarcane Peel.

\section{CONCLUSION}

SPCNC was successfully extracted from sugarcane peel via alkaline treatment, delignification with sodium chlorite and sulphuric acid hydrolysis. Cellulose nanocrystal, comprising of the morphological, size, crystalline and thermal properties were investigated. SEM and TEM micrograph showed that the fiber bundles were separated into individualized $\mathrm{CNC}$, with a needle-shaped $\mathrm{CNC}$ and a particle size value of $20.57 \pm 9.47 \mathrm{~nm}$ in width and $153.05 \pm 70.82 \mathrm{~nm}$ in length. The CNC exhibited an FT-IR spectrum identified as cellulose structures that showed effective removal of the amorphous domain. XRD shows that the CNC retained the cellulose crystalline structure with a crystallinity index of $99.2 \%$, in totality, the crystallinity index rose from $86.5 \%$ in raw to $99.2 \%$ in the cellulose nanocrystal while the TGA curve revealed good thermal stability. The results revealed an effective synthesis of $\mathrm{CNC}$ from sugarcane peel (a waste material from the agricultural process), which have potentials for various industrial applications such as wastewater treatment, bionanocomposites, food packaging among others. 
RASĀYAN J. Chem.

Vol. 13 | No. 1 |177 - 187| January - March | 2020

\section{ACKNOWLEDGMENT}

This study was financially supported by TETFund (Nigeria) through Federal Polytechnic Ilaro, under grant number[AD/R/SC/57/VOL.12/819], NRF/RISA (South Africa), grant number [KIC180412320000]. The authors appreciate Mr. Yunus Kippie of School of Pharmacy, University of the Western Cape, Cape Town, South Africa and the support of Professor Leslie Petrik for offering the laboratory space and equipment of Environmental and Nano Science Group, University of the Western Cape.

\section{REFERENCES}

1. S. Thambiraj and R.D. Shankaran, Journal of Applied Surface Science, 412, 405 (2017).

2. S. Aprilia, B. Arifin, N. Arahman, A. Abubakar, A. Amin, A.V. Wicaksono and D. Bakhtiar, Rasayan Journal of Chemistry, 12(2), 994 (2019), DOI: 10.31788/RJC.2019.1225144

3. K. Xingya, K. Shigenori, W. Chao, Z. Yang, W. Min and H. Yong, American Chemical Society Sustainable Chemical Engineering., 6(3), 2954 (2018), DOI: 10.1021/acssuschemeng.7b02363.

4. K. Anuj, S. N. Yuvraj, C. Veena and K. B. Nishi, Journal of. Materials Physics and Chemistry, 2(1), 1 (2014).

5. H. Chen, Biotechnology of Lignocellulose: Theory and Practice, Chemical Industry Press, Beijing and Springer Science Business Media, Dordrecht, (2014), DOI:10.1007/978-94-007-6898-7_2.

6. I. O. Wulandari, D.J.D.H. Santjojo, R. A. Shobirin and A. Sabarudin, Rasayan Journal of Chemistry, 10(4), 1348 (2017), DOI: 10.7324/RJC.2017.1041907

7. K. Khairan, A. Zahraturriaz and Z. Jalil, Rasayan Journal of Chemistry, 12(1), 50(2019), DOI: 10.31788/RJC.2019.1214073

8. S. H. Yang, Plant Fibre Chemistry, China Light Industry Press, Beijing, p.52 (2008).

9. R. A. Ilyas, S. M. Sapuan and M. R. Ishak, Carbohydrate Polymer, 181, 1038 (2018).

10. R. A. Ilyas, S. M. Sapuan, S. M. Lamaning and I. M. Ridzwan, Current Analytical Chemistry, 13, 67 (2017), DOI: $10.2174 / 157341101366617100315562$.

11. A. I. Inegbenebor, A. O. Inegbenebor and H. I. Boyo, Asian Research Publishing Network Journal of Science and Technology, 2(9), 754(2012).

12. Y. Habibi, L. A. Lucia and O. J. Rojas, Chemical Reviews, 110, 3479 (2010).

13. A. M. Mohamad, W. N. W. Salleh, J. A. F. Juhana, M. A. M. Ismail, B. M. Abu, M. F. M. Zaind, A. A. Nor and A. M. H. Zul, Carbohydrate Polymer, 157, 1892 (2017).

14. P. Lu and Y. Hsieh, Carbohydrate Polymer, 87, 564 (2012).

15. S. Elazzouzi-hafraoui, Y. Nishiyama, J. Putaux, L. Heux, F. Dubreuil and C. Rochas, Biomacromolecule, 9(1), 57 (2008).

16. J. A. Adekoya, E. O. Dare, K. O. Ogunniran, T. O. Siyanbola, O. O. Ajani, C. O. EhiEromosele and N. Revaprasadu, Advances in Natural Sciences: Nanoscience \& Nanotechnology, 7, 1 (2016).

17. http://cirad,fr/en/our-research//tropical value-chains/sugarcane/plants-and uses.

18. O. O. Ashade, R. O. Abubakar, O. O. Nguka, A.O. Yakubu, O. Oyesanya, C. C. Ofoegbu, O. N. Bello and B. A. Osuntade, International Journal of Advances in Pharmacy, Biology and Chemistry, 3(3), 646 (2014).

19. I. Simkovic, J. Mlynar and J. Alfoldi, Holzforschung. 44, 11 (1990).

20. W. Y. Hamad and T. Q. Hu, The Canadian Journal of Chemical Engineering, 88, 392 (2010), DOI: $10.1002 /$ cjce.20298.

21. M. K. S. Rahimi, R. J. Brown, T. Tsuzuki and T. J. Rainey, Advances in Natural Sciences: Nanoscience and Nanotechnology, 7, 1 (2016), DOI:10.1088/2043-6262/7/3/035004.

22. T. I. Shaheen and H. E. Emam, International Journal of. Biological Macromolecules 107, 1599 (2018).

23. S. Naduparambath, T. V. Jinitha, V. Shaniba, M. P. Sreejith, K. B. Aparna and E. Purushothaman, Carbohydrate Polymer, 180, 13 (2018).

24. A O. Ayeni, O. A. Adeeyo, O. M. Oresegun and T. E. Oladimeji, American. Journal of Engineering. Research, 4(4), 14 (2015).

25. C .P. Azubuike, H. Rodríguez, A. O. Okhamafe and R. D. Rogers, Cellulose, 19(2), 425 (2012). 
RASĀYAN J. Chem.

Vol. 13 | No. 1 |177 - 187| January - March | 2020

26. L. Seagal, J. J. Creely, A. E. Martin and C. M. Conrad, Textile Research Journal, 29, 786 (1959).

27. L. Hongjia, G. Yu, Z. Longhui and L. Xiong, Journal of Food Research International, 50, 121 (2013).

28. A. Adewuyi and F. Vargas, Kem. Ind., 66(7-8), 327 (2016).

29. A. Alemdar and M. Sain, Bioresource Technology, 99(6), 1664(2008), DOI:10.1016/j.biortech.2007.04.029.

30. R. Jumaidin, S. M. Sapuan, M. Jawaid, M. R. Ishak and J. Sahari, International Journal of Biological Macromolecules, 99, 265 (2017a), DOI:10.1016/j.ijbiomac.2017.02.092.

31. R. Jumaidin, S. M. Sapuan, M. Jawaid, M. R. Ishak and J. Sahari, International Journal of Biological Macromolecules, 97, 606 (2017b), DOI:10.1016/j.ijbiomac.2017.01.079

32. R. Jumaidin, S. M. Sapuan, M. Jawaid, M. R. Ishak and J. Sahari, European Journal of Phycology, 0 (0), 1 (2017c), DOI:10.1080/ 09670262.2016.1248498.

33. J. Hong and S. Y. Zhang, Journal of China Agricultural University, 10, 90 (2005).

34. H. Lu, Y. Gui, L. Zheng and X. Liu, Food Research International, 50, 121 (2013).

35. C. F. Chau, Y. T. Wang and Y. L. Wen, Food Chemistry, 100, 1402 (2007).

36. W. C Buong, H. L. Syn, A. I. Nor, Y. T. Yoon and Y. L. Yuet, Polymer, (9), 1 (2017), DOI:10.3390.

37. J. Lamaning, R. Hashim, C. P. Leh, O. Sulaiman, T. Sugimoto and M. Nasir, Carbohydrate Polymer, 134, 534 (2015).

38. M. Arup and C. Debabrata, Carbohydrate Polymer, 86, 1291 (2011).

39. P. Garside and P. Wyeth, Studies in Conservation, 48(4), 269 (2003).

40. W. M. Wang, Z. S. Cai, J. Y. Yu and Z. P. Xai, Fibre and Polymer, 10(6), 776 (2009).

41. M. Troedec, D. Sedan, C. Peyratout, J. Bonnet, A. Smith and R. Guinebretiere, Composites Part AApplied Science and Manufacturing, 39(3), 514 (2008).

42. C. S. Julie, G. Neena, K. N. Sunil, Carbohydrate Polymer, 142, 158 (2016).

43. S. Widiarto, S. D. Yuwono, A. Rochliadi and I. M. Arcana, IOP Conference Series: Material Science and Engineering, 176, 1 (2017), DOI:10.1088/1757-899X/176/1/012052.

44. J. Nurain, A. Ishak and D. Alain, Industrial Crops and Products, 37, 93 (2012).

45. B. M. Cherian, A. L. Leão, S. F. de Souza, S. Thomas, L. A. Pothan and M. Kottaisamy, Carbohydrate Polymer, 81(3), 720 (2010), DOI:10.1016/j.carbpol.2010. 03.046.

46. M. M. S. Lima and R. Borsali, Macromolecular Rapid Communication, 25, 771 (2004).

47. N. W. P. Flauzino, H. A. Silvério, N. O. Dantas and D. Pasquini, Industrial Crops and Products, 42, 480 (2013), DOI:10.1016/j.indcrop.2012.06.041.

48. M. Roman and W. T. Winter, Biomacromolecules, 5(5), 1671(2004), DOI:10.1021/bm034519.

49. M. F. Rosa, E. S. Medeiros, J. A. Malmonge, K. S. Gregorski, D. F. Wood, L. H. Mattoso and S. H. Imam, Carbohydrate Polymer, 81(1), 83 (2010).

50. M. R. Ishak, S. M. Sapuan, Z. Leman, M. Z. A. Rahman and U. M. K. Anwar, Journal of Thermal Analysis and Calorimetry, 109(2), 981 (2012), DOI:10.1007/s10973-011-1785-1.

51. H. Yang, R. Yan, H. Chen, D. H. Lee and C. Zheng, Fuel, 86(12-13), 1781 (2007), DOI:10.1016/j.fuel.2006.12.013.

[RJC-5328/2019] 